\title{
Urinary Excretion of Phosphate in Normal Children
}

\author{
N. C. THALASSINOS, BRENDA LEESE, S. C. LATHAM, ${ }^{\star}$ and G. F. JOPLIN \\ From The Endocrine Unit and the Department of Child Health, Royal Postgraduate Medical School, Hammersmith \\ Hospital, London
}

\begin{abstract}
Thalassinos, N. C., Leese, B., Latham, S. C., and Joplin, G. F. (1970). Archives of Disease in Childhood, 45, 269. Urinary excretion of phosphate in normal children. In 55 normal children on a normal diet, the phosphate and creatinine were estimated in a fasting 2-hour urine collection and in a simultaneous blood sample. In comparison with adults, a high serum phosphate and relatively decreased phosphaturia were found, both of which tended to adult values with the advent of puberty. A correlation between the serum phosphate and the urine phosphate/creatinine ratio $(r=+0.42, p<0.002)$ was found. The phosphate excretion index was lower in mid-childhood than in adulthood.

The interpretation of any expression of phosphaturia in childhood requires its own age-specific normal range.
\end{abstract}

The urinary phosphate excretion, though affected by many different hormonal and non-hormonal factors, is mainly dependent on parathyroid activity (Hiatt and Thomson, 1957; Gershberg, Shields, and Kove, 1959; Beutner and Munson, 1960; Arnaud, Tenenhouse, and Rasmussen, 1967). This action of parathyroid hormone has been widely used in the diagnosis of hyper- or hypoparathyroid disorders (Hodgkinson, 1961 ; Bernstein, Yamahiro, and Reynolds, 1965; Nordin and Smith, 1965). Though the phosphaturic action of parathyroid hormone is not questioned, there is no unanimity regarding the best way of expressing phosphaturia and many methods are in use (Bernstein et al., 1965; Nordin and Smith, 1965). We have found that the phosphate excretion index (PEI) of Nordin and Fraser (1960) gives consistent results and is a helpful adjunct in the diagnosis of hyperparathyroidism in the adult (Melvin et al., 1970).

While investigating the cause of hypercalcaemia in a 9-year-old girl who was subsequently shown to have a parathyroid tumour (Latham et al., 1969), we found that the PEI appeared to be lower in children than in adults. We undertook the present study to investigate this apparent discrepancy and to establish a normal range for the PEI in children; it emerged that the normal range was much lower

Received 7 August 1969.

^Present address: Royal Children's Hospital, Herston, Brisbane Q.4029, Australia. than in adults, and that the child we were investigating had an abnormally high value.

\section{Materials and Methods}

Of the 55 children included in the present study, 35 were in-patients for reasons unrelated to disorders of calcium or phosphate metabolism or to endocrine disorders; usually they were in the recovery stage of acute illnesses. The remaining 20 were schoolchildren who, with their parents' consent, offered to act as normal volunteers. The in-patient children were on a normal ward diet while the normal volunteers were on their home diet.

All the children fasted overnight, and first thing in the morning they passed urine which was discarded. After that, an approximate 2-hour urine collection was made, and blood for serum phosphate and creatinine was drawn at about mid-point of the urine collection. On the in-patient children the test was performed on a day that blood was due to be taken for investigations related to the reason of their admission. 5 children who had abnormal renal function as evidenced by a high blood urea or serum creatinine, or produced a urinary volume less than $20 \mathrm{ml}$. were excluded from the present study.

Blood taken was spun within 15 minutes and the serum deep frozen along with an aliquot of the 2-hour urine collection, the estimations being done on a later date. In both serum and urine, the phosphate and creatinine were estimated by auto-analyser (Wootton, 1964). From the values (mg./100 ml.) obtained, we calculated (a) the ratio of urinary phosphate to urinary creatinine concentrations $\left(\mathrm{U}_{\mathrm{p}} / \mathrm{U}_{\mathrm{cr}}\right)$, (b) the ratio of 
phosphate clearance to creatinine clearance $\left(\mathrm{C}_{\mathrm{p}} / \mathrm{C}_{\mathrm{cr}}=\right.$ $\left(\frac{U_{p}}{S_{p}}\right) /\left(\frac{U_{c r}}{S_{c r}}\right)$, and (c) the PEI (PEI $=C_{p} / C_{c r}-$ $\frac{S_{p}-1}{20}$ ) (Nordin and Fraser, 1960).

\section{Results*}

For evaluation of the effect of age on the results, the 55 children were divided according to age into 6 groups, covering the ages 1 to 17 years.

As expected (Greenberg, Winters, and Graham, 1960), the serum phosphate values (Fig. 1) were on the whole higher in the prepubertal groups of children, falling to normal adult values with the advent of puberty.

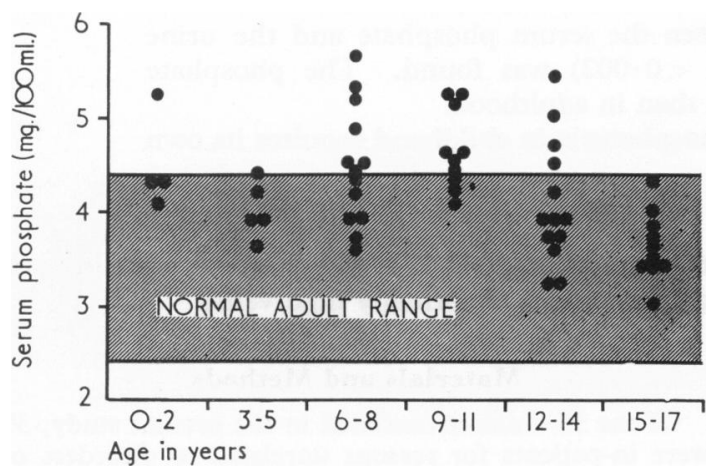

FIG. 1.-Fasting serum phosphate in normal children of different ages. Values fall to the adult range by the age of 15 years.

In spite of the high serum phosphate levels, the PEI (Fig. 2) was found to be decreased in midchildhood, rising to higher values as puberty approached. Values for the PEI within the normal adult range were also commonly observed in the youngest age-groups.

In view of the unexpected finding of a low PEI along with a high serum phosphate, we separately analysed the parameters involved in the PEI. The urinary phosphate/creatinine ratio $\left(U_{p} / U_{c r}\right)$ was found (Fig. 3) to be the highest in the infants, falling to adult values ( 32 of 33 tests) above the age of 9. There is thus a similarity of the age-effect on serum phosphate and urinary phosphate/creatinine ratio $\left(U_{p} / U_{c r}\right)$ in Fig. 1 and 3. Hence, when the serum phosphate and $U_{p} / U_{c r}$ ratios were compared

\footnotetext{
*A table giving full numerical results can be obtained by writing to the Librarian. Nuffield Library, B.M.A. House, Tavistock Square, London W.C.1.
}

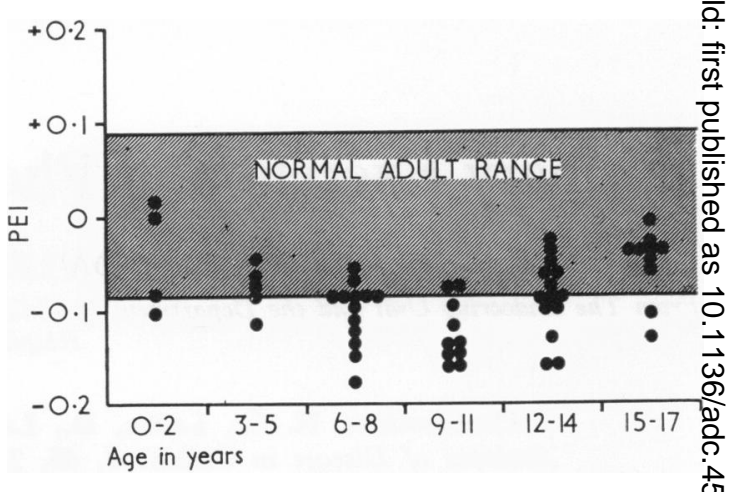

FIG. 2.-Phosphate excretion index in normal children of different ages. The PEI is usually below the adult range in children, rising towards adult values in adolescence Infants, with their high milk intake, often have adulø values.

in the 51 children aged 3 and over (Fig. 4) it wass found that a definite correlation existed $(r=+0 \cdot 42$, $\mathrm{p}<0.002)$. The regression line approximates that of Nordin and Fraser (1960) for adults. Our infants aged $1 \frac{1}{2}-2$ years, however, showed very much higher $U_{p} / U_{c r}$ values than the children and so are not included in Fig. 4. However, if we only consides the 27 children aged $3-11$, the regression line fallso much lower $(y=0 \cdot 165 x-0 \cdot 246)$.

The calculation of the more elaborate ratio of the clearances of phosphate to creatinine $\left(\mathrm{C}_{\mathrm{p}} / \mathrm{C}_{\mathrm{cr}} \overrightarrow{\mathrm{E}}\right.$ gave values that were mainly in the lower half of the normal range (Fig. 5); again the infants showed very much higher values. When the values of $\mathrm{C}_{\mathrm{p}} / \mathrm{C}_{\mathrm{cr}}$ were plotted against the serum phosphatey no correlation was shown, and the scattergram is?

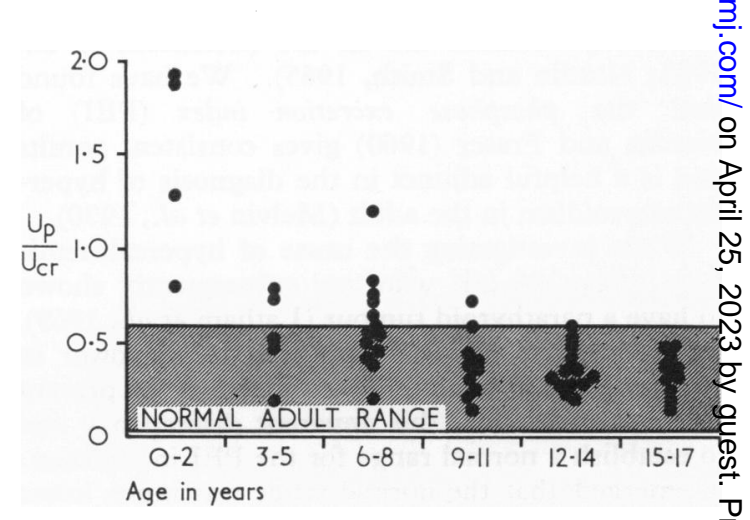

FIG. 3.-Urine phosphate/creatinine ratio at differen ages. The $U_{p} / U_{c r}$ ratio falls from very high levels $i{ }_{P}$ infants to reach adult values in adolescence. 


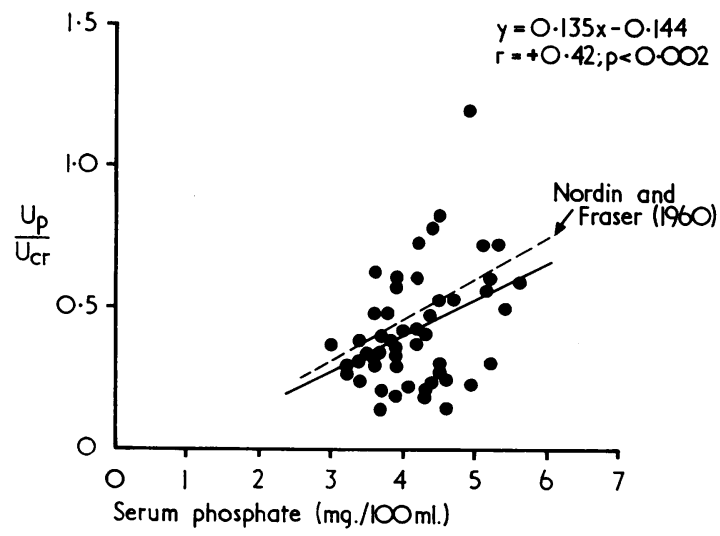

FIG. 4.-Urine phosphate/creatinine ratio related to serum phosphate. The urine p/cr ratio was plotted against serum phosphate for the 51 children aged 3 and above, and the continuous regression line obtained. For comparison, the regression line reported by Nordin and Fraser (1960) based on studies in (53 normal) adults is drawn as an interupted line.

not published. However, when these plots were examined against the normal adult range of Nordin and Fraser (1960) all showed a value of $C_{p} / C_{c r}$ below the mean adult value.

\section{Discussion}

The finding of a low PEI in children has been previously alluded to; Taitz and De Lacy (1962) refer to a range of +0.04 to -0.22 in 8 'normal' infants, which agrees well with the range found in our normal children (Fig. 2). Clearly the PEI in a child can only be interpreted by comparison with the normal range for the same age-group, such as indicated in Fig. 2. Similarly, if the simpler measurements of $\mathrm{U}_{\mathrm{p}} / \mathrm{U}_{\mathrm{cr}}$ or $\mathrm{C}_{\mathrm{p}} / \mathrm{C}_{\mathrm{cr}}$ are used, an effect of age is seen (Fig. 3 and 5).

The only other study of phosphaturia in normal children that we are aware of is that of Janse, Van Gelderen, and Ruys (1966). Using 24-hour urine collections, they were unable to show any relation between the fasting serum phosphate level and either the value $\mathrm{C}_{\mathrm{p}} / \mathrm{C}_{\mathrm{cr}}$ or the value $\mathrm{U}_{\mathrm{p}} / \mathrm{U}_{\mathrm{cr}}$. In contrast, our series using 2-hour fasting urine collections and mid-point blood samples does show a relation between serum phosphate and $U_{p} / U_{c r}$ (Fig. 4); probably the difference in these findings is due to the use of 24-hour collections by Janse's group, as there is a well-known effect of diet and time of day upon the excretion of phosphate and creatinine (Stanbury and Thomson, 1951; Briscoe and Ragan, 1966).

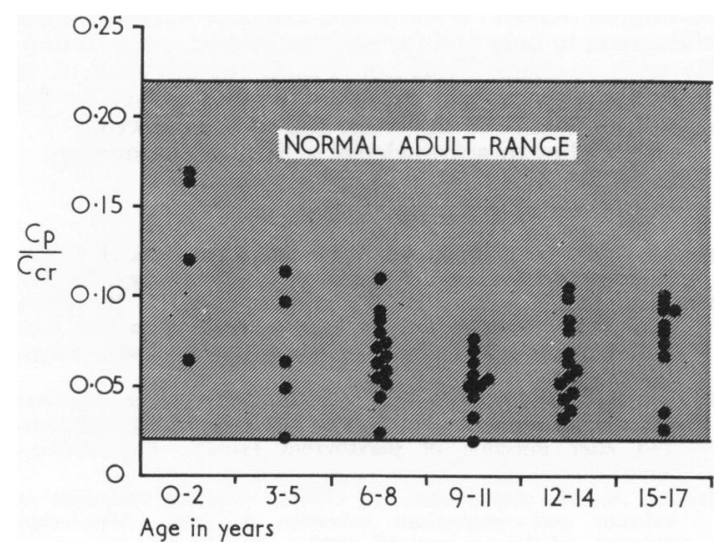

FIG. 5.-Phosphate clearance/creatinine clearance ratio at different ages. The $C_{p} / C_{e r}$ values are mainly in the lower half of the normal range.

Not surprisingly their values for $U_{p} / U_{c r}$ in fed children were much higher than ours, yet the serum phosphate levels are similar in the two series, both being obtained before breakfast. However, our series of children, like normal adult series under basal conditions (Nordin and Fraser, 1960), failed to show any correlation between serum phosphate and $\mathrm{C}_{\mathrm{p}} / \mathrm{C}_{\mathrm{cr}}$. Possibly the loss of relation when this expression is used is due to the fact that the serum phosphate appears in the denominator of the formula for $\mathrm{C}_{\mathrm{p}} / \mathrm{C}_{\mathrm{cr}}$ and hence obscures the effect of the serum phosphate on phosphate excretion.

The reason for the lower phosphate excretion in relation to the serum phosphate in children, whether expressed as $U_{p} / U_{c r}$ (Fig. 4), $C_{p} / C_{c r}$, or the PEI (Fig. 2) is probably multiple. It is unlikely that it is due to a low level of phosphate intake, as our children were all on normal diets, but may well be due to higher tubular reabsorption of phosphate possibly from higher growth hormone activity (Greenwood, Hunter, and Marrian, 1964; cp. Della Casa, 1968). Infants, however, have a higher phosphate excretion than older children (Fig. 2, 3 , and 5), possibly due to the high milk content of their diet.

Though the present paper cannot examine the relative diagnostic value of the various indices of phosphaturia, it is clear that whatever index is employed, an age-specific normal range is required.

We would like to express our thanks to Dr. A. D. Badcock, Headmaster, and to the boys of St. Clement Danes Grammar School (Du Cane Road, London W.12), and to Mrs. E. Moore, Headmistress, and the girls of 
Burlington School (Wood Lane, London W.12) for their willingness to help and for their unlimited co-operation. We wish to thank Professor Tizard for allowing us to study his patients, and Professor Russell Fraser for his helpful criticisms of the work and the manuscript.

N.T. wishes to acknowledge a Sandoz Fellowship.

\section{REFERENCES}

Arnaud, C. D., Jr., Tenenhouse, A. M., and Rasmussen, H. (1967). Parathyroid hormone. Annual Review of Physiology, 29, 349.

Bernstein, M., Yamahiro, H. S., and Reynolds, T. B. (1965). Phosphorus excretion tests in hyperparathyroidism with controlled phosphorus intake. Fournal of Clinical Endocrinology, 25, 895.

Beutner, H. E., and Munson, P. L. (1960). Time course of urinary excretion of inorganic phosphate by rats after parathyroidectomy and after injection of parathyroid extract. Endocrinology, 66, 610 .

Briscoe, A. M., and Ragan, C. (1966). Diurnal variations in calcium and magnesium excretion in man. Metabolism, Clinical and Experimental, 15, 1002.

Della Casa, L. (1968). Studies on several factors influencing a double antibody radioimmunoassay of human growth hormone in plasma. In Growth Hormone, p. 116. Ed. by A. Pecile and E. E. Müller. Excerpta Medica Foundation, Amsterdam.

Gershberg, H., Shields, D. R., and Kove, S. S. (1959). The acute effects of parathyroid extract in states of edema, diminished renal function and parathyroid disease. fournal of Clinical Endrocrinology, 19, 681.

Greenberg, B. G., Winters, R. W., and Graham, J. B. (1960), The normal range of serum inorganic phosphorus and its utility as a discriminant in the diagnosis of congenital hypophosphatemia. Fournal of Clinical Endocrinology, 20, 364.
Greenwood, F. C., Hunter, W. M., and Marrian, V. J. (1964 $\Omega$ Growth-hormone levels in children and adolescents. Britist. Medical fournal, $1,25$.

Hiatt, H. H., and Thomson, D. D. (1957). The effects of parathyroid extract on renal function in man. Fournal of Clinicas Investigation, 36, 557.

Hodgkinson, A. (1961). Renal phosphate excretion indices in the diagnosis of hyperparathyroidism. Clinical Science, 21, 1250

Janse, H., Van Gelderen, H. H., and Ruys, J. H. (1966). Assess ment of urinary phosphate excretion in normal and abnormat children. Archives of Disease in Childhood, 41, 541.

Latham, S. C., Bordier, P., Doyle, F. H., Higgs, F. D., Joplin, G. F을 Taylor, S., and Thalassinos, N. C. (1969). A case of milö hyperparathyroidism in childhood. Archives of Disease in. Childhood, 44, 521.

Melvin, K. E. W., Joplin, G. F., Taylor, S., and Fraser, T. R. (1970) Bone tracer and phosphaturia measurements in the diagnosis of primary hyperparathyroidism. Submitted for publication.

Nordin, B. E. C., and Fraser, R. (1960). Assessment of phosphate excretion. Lancet, $1,947$.

—, and Smith, D. A. (1965). Diagnostic Procedures in Disorders $\not \mathcal{P}$ Calcium Metabolism, p. 35. Churchill, London.

Stanbury, S. W., and Thomson, A. E. (1951). Diurnal variations in electrolyte excretion. Clinical Science, 10, 267.

Taitz, L. S., and De Lacy, C. D. (1962). Parathyroid function is vitamin D deficiency rickets. I. Phosphorus excretion indeio in vitamin $\mathbf{D}$ deficiency rickets in South African Bantu infant Pediatrics, 30, 875.

Wootton, I. D. P. (1964). Micro-Analysis in Medical Biochemistry? 4th ed. p. 26. Churchill, London.

Correspondence to Dr. N. C. Thalassinos, Royal Posto graduate Medical School, Hammersmith Hospital, London W.12. 